\title{
The Effect of Strategy on Problem Solving: An fMRI Study
}

\author{
Sharlene D. Newman', Benjamin Pruce', Akash Rusia', \\ and Thomas Burns Jr. ${ }^{1}$
}

\begin{abstract}
:
fMRI was used to examine the differential effect of two problem-solving strategies. Participants were trained to use both a pictorial/spatial and a symbolic/algebraic strategy to solve word problems. While these two strategies activated similar cortical regions, a number of differences were noted in the level of activation. These differences indicate that the algebraic strategy is more demanding than the spatial strategy, which was particularly true for the anterior insula and the parietal cortices. In addition, an exploratory analysis was performed that examined effects of strategy preference. These results revealed that participants who preferred the algebraic strategy, while having a similar mathematics background, elicited less activation and had higher working memory capacity (as measured by the reading span task) than those participants who preferred the spatial strategy. These data have implications for $\mathrm{fMRl}$, as well as behavioral studies of higher-order cognition-the use of different strategies by participants within one study could alter the final results and, therefore, the conclusions drawn.
\end{abstract}

\section{Keywords:}

problem solving, $\mathrm{fMRI}$, strategy, algebra

Acknowledgments:We would like to thank John Greco, Kristen Ratliff, and Tara Muratore for all of their help with data collection. This research was supported in part by the Indiana METACyt Initiative of Indiana University, funded in part through a major grant from the Lilly Endowment, Inc.

'Indiana University, Bloomington 


\section{Introduction}

When confronted with a problem we develop an action plan or strategy to solve it. But how do we develop that strategy and how do we choose which one of multiple strategies to select for the current problem? There appears to be a number of factors that influence strategy formation and selection. For example, the ability to think about a problem in multiple ways (cognitive flexibility) seems to enhance the ability to learn more about the problem (Graham \& Perry, 1993; Siegler, 1995), which in turn allows for the development of more efficient problem-solving strategies. Also, the more information (relevant rules, strategies, conceptualizations) an individual has about a given problem the more likely she or he is to fit a strategy to it, or to select the most appropriate strategy (Siegler et al., 1996). All of this goes to show:(1) that there is typically more than one way to solve a problem, and (2) that ability and experience both impact the strategy chosen.

The use of functional neuroimaging techniques to study more complex cognitive functions has grown significantly. Although it has been demonstrated that there is variability in the strategies used in complex tasks (Kwong \& Varnhagen, 2005; LeFevre et al., 1996; Rogers, Hertzog, \& Fisk, 2000), this variability is seldom accounted for. However, an understanding of how strategy differences may impact the underlying neural network is extremely important.It can, for example, help to explain the increase in variance observed when examining higher-order cognitive tasks compared to perceptual tasks. Studying the effect of strategy differences can also be expected to provide a clearer picture of the functional properties of neural networks.

In order to begin to address this issue we have examined problem solving. The problem used here is a verbal reasoning problem that we have used previously (Newman et al., 2002). The problems were patterned after the following prototype, which has proven to be enigmatically difficult (Casey, 1993):"Imagine that a man is looking at a photograph while saying,

'Brothers and sisters have I none. That man's father is my father's son.

Who is in the photograph?"

In a study with 101 adult participants, $77 \%$ of the respondents chose the same incorrect answer (the man himself), while only $13 \%$ chose the correct answer (it is a photograph of the man's son). Casey suggested that the various processing demands of this riddle may exceed verbal working memory capacity. One such demand arises from the order of the two phrases That man's father and my father's son. These demands are related to those observed in sentence comprehension. Earlier comprehension studies indicated that processing is slower when the given information follows rather than precedes the new information - which is the case for the hard problems where the favorite (the new information) precedes the given information (Haviland \& Clark, 1974; Clark 1977).Furthermore, it has been suggested that the reason for the slower processing is due to a reordering, 
or manipulation, of the sentence constituents (Carpenter \& Just, 1977). Taking Casey's original problem you would have "My father's son is that man's father" and it was shown that significantly more people correctly answered this version of the problem (accuracy increased to as high as $90 \%$ ).

In the current event-related fMRI study we developed two versions of the "brothers" riddle that varied the order of the two noun phrases that demonstrate differences in the timing of cortical responses that subserve part of the working memory network. In the first problem type (easy: The month after April is the month before my favorite month), comprehending the first phrase (the given information) of the sentence requires a computation (computing the referent of "the first month after April"), whereas no such corresponding computation is required for the second phrase (the new information). By contrast, in the second problem type (hard: The month before my favorite month is the month after April), the reverse is true. Based on the new/given ordering it is expected that the hard problems will place a larger load on working memory processes. Also, as suggested by Carpenter and Just (1977), it is to be expected that to solve the hard problems the problem will be reordered in a format similar to that of the easy problems.

In a small pilot study using these problems in which the two phrases were presented separately it was revealed that participants generated two strategies rather consistently (some participants were unable to articulate their strategy) — a symbolic strategy and a spatial strategy. The symbolic strategy reported by participants involved the conversion of the word problem into an equation.Participants described converting favorite to a variable, most often $x$, so using the easy example above, they reported "adding" one to April and holding that information until the second phrase was presented and then if the second phrase contained before they would add the number of months before to what was being held in memory. The interesting point is that those who reported using this strategy used math terms like adding and subtraction and $x$ (as a variable) when describing how they performed the task. All of these terms suggest the use of a symbolic mathematical algorithm that we will refer to here as an algebraic strategy.

The spatial strategy was qualitatively very different. Individuals using the spatial strategy reported imagining a number line of sorts with the months, in the case of the example, as bins. They reported beginning by starting at the April bin and moving left (before) or right (after); they would then hold the number line in memory with the new position being the focus. After reading the second phrase they would then, in the case of the easy example, look to see which month the current location is before. The description of the spatial strategy, unlike the algebraic strategy, contained no mathematical terms and used the spatial relations provided in the problem (e.g., before and after).

In the current study, we have used these two, participant-developed strategies to explore how they differentially affect problem-solving processes. These two strategies are quite interesting in that they represent two types of strategies to solve word problems that 
have been investigated for many years - pictorial/model and symbolic/equation methods. The pictorial representations make explicit the important relationships and may, therefore, aid in problem comprehension; this is not necessarily true in the symbolic representation. In fact, it has been found that participants perform better when provided with a pictorial representation (Koedinger \& Terao, 2002; Lewis, 1989). However, here, participants are not provided with a pictorial representation. Either they are to use a strategy in which they generate one mentally to aid in problem solving or they are told to generate a more symbolic representation mentally.

In order to help ground the study, we used the ACT-R model of problem solving/ cognition developed by Anderson and colleagues (described most recently in Anderson et al., 2008) as a basis of comparison. The latest version of the ACT-R model described by Anderson and colleagues (2008) involves four major modules:an imaginal module responsible for constructing internal representations that is linked to parietal cortex; a declarative memory retrieval module linked to the lateral prefrontal cortex; a module responsible for the setting of controlling goals linked to the anterior cingulate; and a procedural execution module linked to the head of the caudate nucleus, a part of the basal ganglia. These modules are thought to be central to most of cognition and according to the ACT-R theory these basic operations are cycled through in order to complete a cognitive task. Here we focus on three of these modules, the imaginal, the declarative memory retrieval, and the setting of controlling goals modules.

The imaginal module is thought to be involved in the maintenance and transformation of internal representations. There is extensive neuroimaging and neuropsychological data to support the posterior parietal cortices' involvement in these processes (Carpenter et al., 1999; Newman et al., 2007, 2003; Zacks et al., 2008). For example, in studies examining the Tower of London task both the left and right posterior parietal cortex have been found to be involved in the spatial processing necessary to solve the task, including spatial working memory and spatial attention (Newman et al., 2003). In addition, Danker and Anderson (2007) examined the neural bases of transformation and retrieval processes during algebra problem solving and found the posterior parietal cortex was closely linked to these transformation processes. Based on the previous studies, the imaginal module may be predicted to be involved in both the algebraic and spatial strategies. One question that is addressed here is whether one strategy relies more heavily on these transformation processes than the other.

The declarative memory retrieval module, located in the lateral prefrontal cortex, is involved in both the retrieval and the selection of information from memory stores. It has been found that how long information must be held as well as the difficulty in selecting the appropriate information from memory drives the processing of this module. For example, Gold and Buckner (2002) found that the lateral inferior prefrontal cortex was involved in controlled retrieval from memory for both semantic and non-semantic information. In that 
study a semantic task (deciding whether a visually presented word is abstract or concrete) and a non-semantic task (deciding whether visually presented words and pseudowords contain a long or short vowel) requiring controlled retrieval of information from memory were found to elicit the involvement of the lateral prefrontal cortex. In the current study this region is thought to be involved in the retrieval of information such as arithmetic facts or months of the year from long-term memory stores.

The setting of controlling goals module, associated with the anterior cingulate cortex (ACC), is thought to be responsible for indicating the state transitions during problem solving. These processes are analogous to the cognitive control and error likelihood processes that have been previously linked to the ACC (Botvinick et al., 2001; Brown \& Braver, 2005; MacDonald et al.,2000). For example, Brown and Braver (2005) showed that the ACC learned to predict the likelihood of committing an error for a given condition during a stop-signal task using both $\mathrm{fMRI}$ and a computational model of the region. In addition, the ACC has been found to respond to task difficulty, particularly when difficulty is defined by the increase in the number of mental steps (Newman et al., 2009; Anderson et al., 2008). However, it can be argued that when task difficulty increases the likelihood of committing an error also increases. In the current study the ACC is expected to be more involved when solving the hard problems, particularly if we assume, as is suggested above, that during the hard problems participants reorder the phrases before solving. This reordering is an additional step that could increase the likelihood of error and, therefore, increase the activation within the region. It is not clear at this point if differences as a function of strategy are expected in this region. There is no reason to assume that the error likelihood is different as a function of strategy.

In sum, the primary aim of this study is to better characterize how strategy differences impact the underlying neural network that supports problem solving by examining two qualitatively different strategies. As suggested above, while the algebraic and spatial strategies appear to be quite different, they are expected to rely on very similar cognitive processes and, as a consequence, may be expected to rely on similar brain structures. For example, for both strategies there is the conversion of the word problem into a different internal representation (one a number line and one an equation), the maintenance of that representation in working memory, and the transformation of that representation (moving the ball in one and isolating the $x$ in the other). While both strategies are expected to rely on overlapping brain regions, subtle differences in how much they rely on these regions are expected (i.e., the amount of activation in these regions are expected to vary with strategy). For example, even though both strategies rely on working memory it may be that the algebraic strategy relies heavily on verbal working memory while the spatial strategy does not; therefore, greater involvement of regions linked to verbal working memory such as the anterior insula or the inferior parietal cortex (Awh et al. 1996; Carpenter, Just, \& Reichle, 2000;D'Esposito et al. 1999; Postle, Berger, \&D'Esposito, 1999;Smith and Jonides

- volume 3, no. 1 (Fall 2010) 
1999) may be expected when using the algebraic strategy. Another difference may be in the amount of declarative memory retrieval necessary. Long-term memory retrieval is required for both strategies; however, the algebraic strategy may be predicted to rely more on retrieval processes if we assume that the strategy requires the association between the terms before and after with the arithmetic symbols of addition and subtraction.

\section{Methods}

Participants. A total of 23 individuals from the Indiana University community participated in the study. Data from six participants were not used in the data analysis due to excessive errors (> 40\%), or an inability to consistently use the instructed strategy. The data from the remaining participants, 17 young adults (mean age $=24.1,18-44 ; 7$ females, 10 males), are reported here. All participants were right-handed, native English speakers and all participants gave written informed consent approved by the IRB committee of Indiana University prior to their participation.

Materials. The stimuli consisted of two levels of difficulty of verbal problems (easy versus hard) as shown in the examples above. Three additional variables were manipulated to introduce superficial variation among the problems: (1) distance from the reference point (e.g., the first, second, or third month after); (2) direction from reference point (i.e., before or after), and (3) problem domain (e.g., days, months, or letters).

Two problem-solving strategies were examined. The first was a spatial strategy. This strategy required participants to solve the problems by imagining moving backward and forward along a number line. The second strategy examined was an algebraic strategy in which participants were required to convert the verbal problem into an equation, substituting favorite for $x$ and then solve for $x$-as described in the introduction (see Figure 1).

A mixed event-related design was employed in which blocks of four trials were presented with the strategy to be used being displayed at the beginning of the block for one second. Each block contained two easy and two hard problems randomly ordered. The sentences were projected onto a transparent screen and viewed by the participant via a mirror attached to the head coil. The first half of the sentence, phrase 1, was presented alone on the screen for $4 \mathrm{sec}$ (with a 500 msec delay after). Afterward the second half of the sentence, phrase 2, was presented alone for $4 \mathrm{sec}$ (with a $500 \mathrm{msec}$ delay after). The probe, which consisted of two possible targets and "Other," was then presented alone on the screen for $3 \mathrm{sec}$ (see Figure 2). The timing of presentation was obtained by taking the time that corresponded to $75 \%$ of the trials in pilot data. Each trial was followed by a 12 sec rest period to allow for the hemodynamic response to approach baseline. Four 6.7 minute runs were presented with a total of 64 problems. Each run contained two $24 \mathrm{sec}$ fixation periods, one at the beginning and one at the end, in order to obtain a common baseline for comparison. 

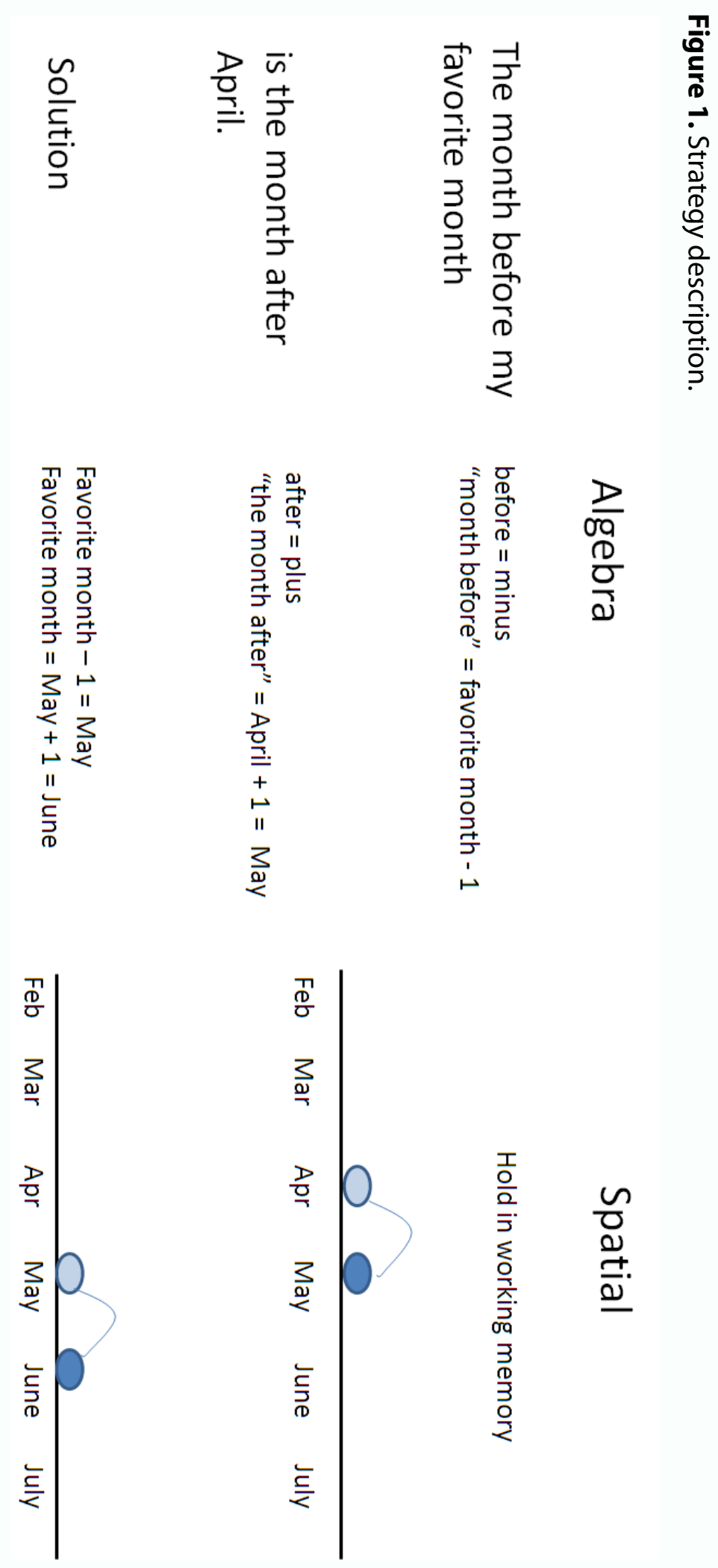

- volume 3, no. 1 (Fall 2010) 
Figure 2. Timing of each trial.

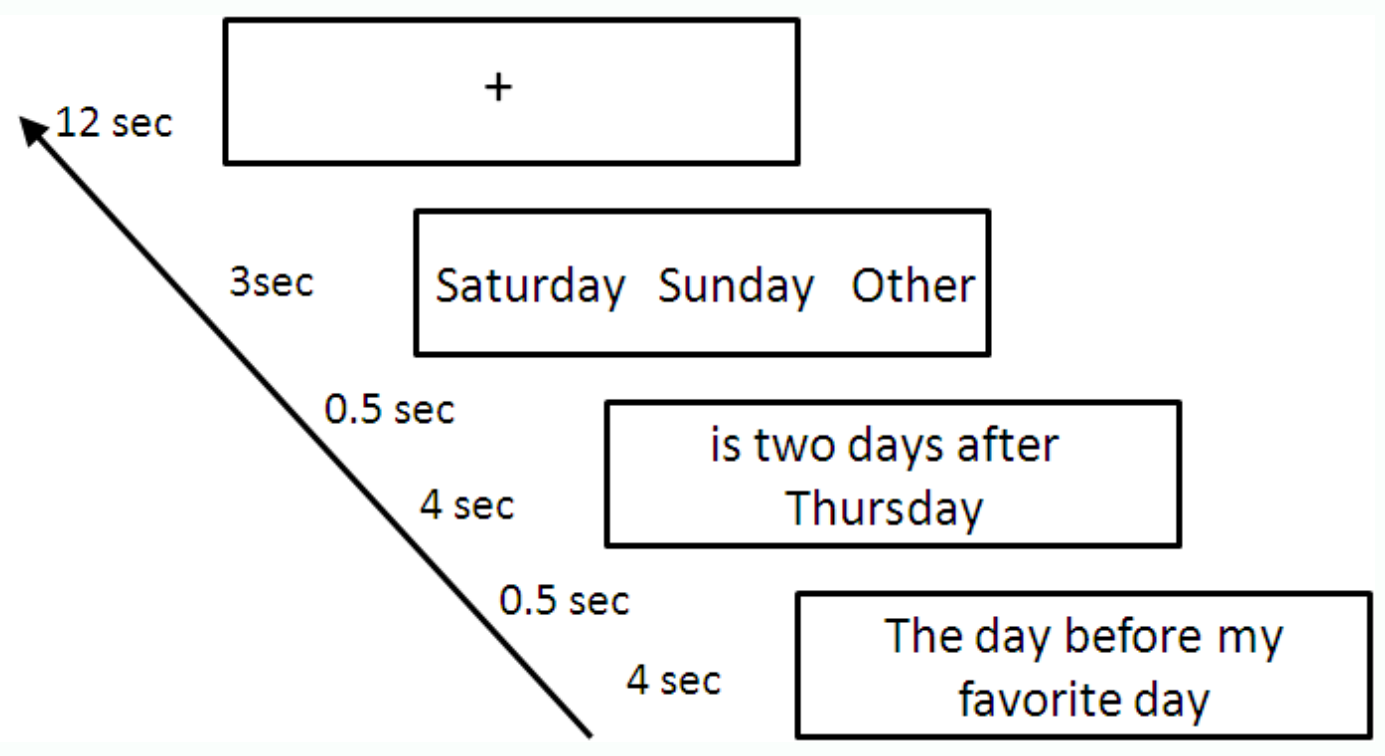

Procedure. Participants took part in a training session prior to scanning. During this session participants completed a paper-and-pencil training task that prepared them for the actual computer-based experimental task. During this training the experimenter presented the participants example problems and explained the two strategies. After explaining the strategies, the experimenter then demonstrated, on paper, how to use both the spatial and algebraic strategies with both the easy and hard problems (see Figure 1). After the demonstration, participants then completed 16 problems using paper and pencil and were required to write out each step or draw the number line. The first eight were solved using the spatial strategy while the second eight were solved using the algebraic strategy. There were an equal number of easy and hard problems in this practice. Their performance was checked to determine that they could solve the problems using the appropriate strategy. If they failed to understand either of the strategies after the paperand-pencil problem-solving portion of the training they did not go on to the next part of the training session but instead participated in another study being conducted in the lab. Participants then were administered the experimental computer training that had the same timing restrictions as the actual imaging version of the experiment in order to expose the participants to the task and to ensure that they were able to perform the task under the time constraints required and without paper and pencil.Only participants who could perform the task, who understood both strategies, and who could perform the task under the computer-based conditions were scanned. Other participants were directed to other ongoing studies. These steps were taken to ensure that only participants who could use both strategies and who could adequately perform the task were scanned.The 
ancillary behavioral study described below, however, did not have a performance criterion and includes a wider range of participants.

A debriefing was performed after the training session and after the scanning session. The debriefing questions were designed to determine how well the participants understood and were able to use both strategies when instructed. In addition, information regarding their math background (the highest-level math class taken) was obtained as well as measures of spatial processing ability, via the Vandenberg mental rotations task (Vandenberg, 1971), and working memory capacity, via the reading span task (Daneman \& Carpenter, 1980). During the debriefing participants were also asked which strategy, either the algebraic or spatial strategy, they preferred to use or that they considered easier to use.

fMRI Acquisition and Analysis. The images were acquired on a 3T Siemens TRIO scanner with an 8-channel radio frequency coil located in the Imaging Research Facility at Indiana University. The functional images were acquired in $185 \mathrm{~mm}$ thick oblique axial slices using the following parameters: $\mathrm{TR}=1000 \mathrm{msec}, \mathrm{TE}=25 \mathrm{msec}$, flip angle $=60^{\circ}$, voxel size $=$ $3.125 \mathrm{~mm} \times 3.125 \mathrm{~mm} \times 5 \mathrm{~mm}$ with a $1 \mathrm{~mm}$ gap.

The data were analyzed using statistical parametric mapping (SPM5 from the Wellcome Department of Cognitive Neurology, London).Images were corrected for slice acquisition timing, and resampled to $2 \times 2 \times 2 \mathrm{~mm}$ voxels. Images were subsequently smoothed in the spatial domain with a Gaussian filter of $8 \mathrm{~mm}$ at full-width at half maximum. The data were also high-pass filtered with $1 / 128 \mathrm{~Hz}$ cutoff frequency to remove low-frequency signals (e.g., linear drifts).The images were motion-corrected and the motion parameters were incorporated in the design estimation. The functional, EPI images were registered and normalized to the Montreal Neurological Institute (MNI) EPI template. At the individual level, statistical analysis was performed on each participant's data by using the general linear model and Gaussian random field theory as implemented in SPM5. Each event (trial) was convolved with a canonical hemodynamic response function and entered as regressors in the model (Friston et al., 1995). Although there were three phases for each trial (phrase 1, phrase 2, and response) only one regressor that encompassed all phases was used in this analysis.

Analysis was performed based on a set of predefined regions of interest (ROls). The ROIs were based on a series of studies by Anderson and colleagues (Anderson et al., 2004; Qin et al., 2004; Rosenberg-Lee, Lovett, \& Anderson, 2009; Stocco \& Anderson, 2008) and included the left prefrontal cortex (the declarative module), the left and right parietal cortices (the imaginal module), the bilateral anterior cingulate cortex (the setting of controlling goals module), and the head of the caudate (the procedural execution module). These ROls were defined by using the coordinates reported in Anderson et al. (2008). In addition to these regions the left anterior insula was also examined. The center coordinates for the anterior insula ROI were defined using the conjunction map, which revealed 
common activation across all conditions with a threshold of $p<0.05$, corrected for multiple comparisons using familywise error correction. All ROls were defined as a sphere with a radius of $5 \mathrm{~mm}$ and center defined by the coordinates listed in Table 1. Using the Marsbar toolbox (Brett et al.2002), averaged timecourse data from voxels within an ROI were computed for each individual's imaging dataset and sorted by experimental condition. The averaged timecourses across all trials were converted into percentage signal change (PSC) using the formula (signal - baseline/ baseline) $\times 100$ for each time point, where the baseline constant was the mean signal of the fixation periods. Then, the PSC timecourses were baseline corrected to 0 .

In addition to the ROI analysis, the random effects analysis on group data was performed using a one-sample $t$-test. Activated brain areas were defined using an uncorrected threshold of $p<0.001$ and a cluster extent threshold of greater than 20 voxels and were rendered on a template brain in SPM5. An exploratory analysis was also performed to examine strategy preference effects.

\section{Results}

Behavioral Results. Even though much of the actual problem solving takes place when processing the first and second phrases, the response time to the probe was examined. The response time to the probe, as well as the error rate, was subjected to a $2 \times 2$ withinparticipant ANOVA. For response time, main effects of difficulty $[F(1,16)=24.12, p<0.001]$ and strategy $[F(1,16)=8.7, p<0.01]$ were observed, with the hard problems and problems solved using the spatial strategy taking longer to respond to. There was no interaction $[F(1,16)=1.92, p>0.1]$. The error rate analysis revealed main effects of difficulty $[F(1,16)=$ $30.06, p<0.0001]$ and strategy $[F(1,16)=6.03, p<0.05]$, with the spatial strategy having fewer errors. There was no significant interaction $[F(1,16)=2.75, p>0.1]$ (see Figure 3 ).

A between-subjects ANOVA was performed to examine the effect of strategy preference. Reaction time was found to show a significant effect of preference $[F(1,6)=11.29$, $p<0.005]$, with the algebra preference group showing a slower reaction time. Error rate failed to show an effect of strategy preference $[F(1,6)=3.53, p=0.067]$, but did reveal an interaction between difficulty and preference $[F(1,6)=4.2, p<0.05]$ due to the lack of an effect for the easy problems.

Activation Differences in Predefined ROls. Of the predefined ROls, bilateral parietal cortex, anterior cingulate, left prefrontal cortex, and the anterior insula revealed effects of strategy, with the algebraic strategy eliciting greater activation (see Table 1). Based on the ACT-R model, these data suggest that the algebraic strategy has more demanding memory retrieval, setting of controlling goals, and representation construction processes than the spatial strategy. Also, because the anterior insula has been strongly linked to verbal working memory processes (Awh et al., 1996; Carpenter, Just, \& Reichle, 2000; D'Esposito et al., 
Table 1. Predefined ROIs

\begin{tabular}{|l|l|l|l|}
\hline \multicolumn{2}{|l|}{} & Effects: $F(1,16)$ & $\begin{array}{l}\text { MNI coordinates } \\
x, y, z\end{array}$ \\
\hline Lef & 7 & $\begin{array}{l}\text { Strategy: } 6.1^{*} \\
\text { Difficulty: } 1.36 \\
\text { Interaction: }<1\end{array}$ & $-24,-62,40$ \\
\hline Right Superior Parietal Lobe & 7 & $\begin{array}{l}\text { Strategy: } 4.5^{*} \\
\text { Difficulty: } 5.94^{*} \\
\text { Interaction: }<1\end{array}$ & $26,-54,41$ \\
\hline Left Prefrontal Gyrus & 46 & $\begin{array}{l}\text { Strategy: } 12.61^{*} \\
\text { Difficulty:5.51* } \\
\text { Interaction: }<1\end{array}$ & $-42,30,24$ \\
\hline Left Anterior Insula & 13 & $\begin{array}{l}\text { Strategy: } 12.59^{*} \\
\text { Difficulty: }<1 \\
\text { Interaction: }<1\end{array}$ & $-33,21,6$ \\
\hline Left Anterior Cingulate & 32 & $\begin{array}{l}\text { Strategy: } 4.37^{*} \\
\text { Difficulty: }<1 \\
\text { Interaction: } 1.84\end{array}$ & $-5,8,47$ \\
\hline Right Anterior Cingulate & 32 & $\begin{array}{l}\text { Strategy: }<4.89^{*} \\
\text { Difficulty: }<1 \\
\text { Interaction: } 2.69\end{array}$ & $5,8,47$ \\
\hline
\end{tabular}

Note: ${ }^{*} p<0.05$.

Figure 3. Behavioral data.

\section{Behavioral Results}

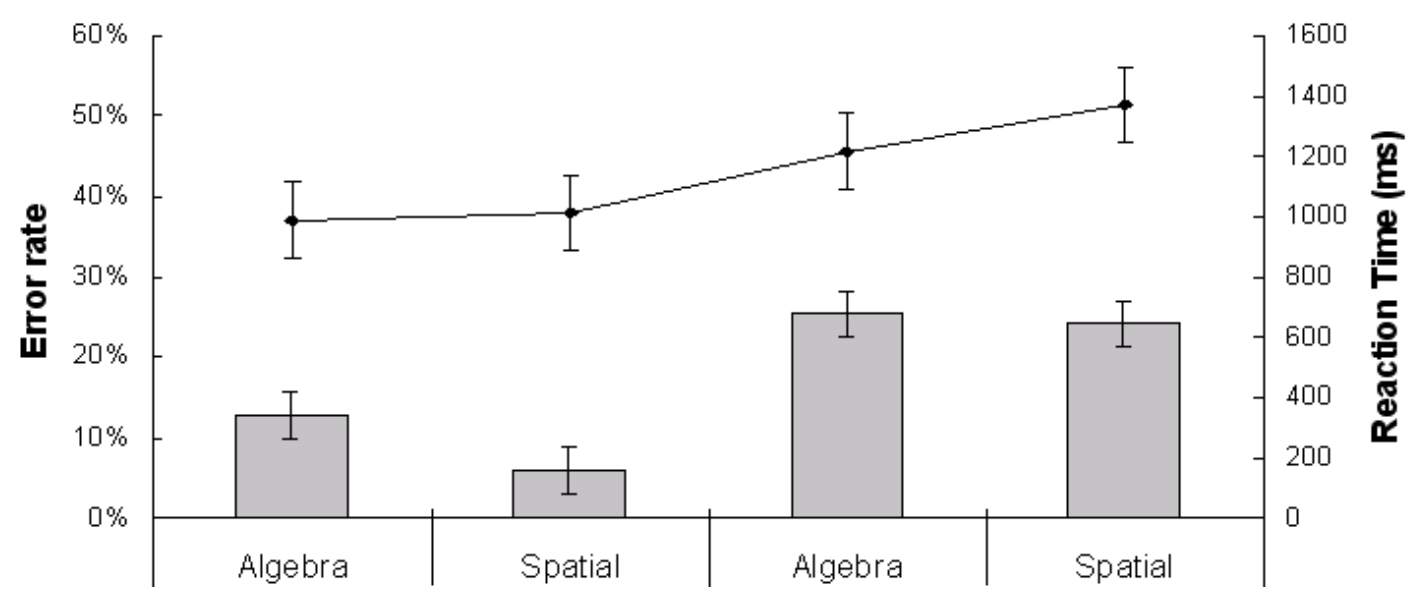

- volume 3, no. 1 (Fall 2010) 
1999; Postle, Berger, \& D'Esposito, 1999; Smith \& Jonides, 1999), the results also suggest that the algebraic strategy has greater working memory demands.

None of the predefined regions revealed greater activation for the spatial strategy compared to the algebraic strategy. Within the predefined regions, difficulty effects were observed in the left prefrontal cortex and right parietal cortex, with the hard problems eliciting greater activation. None of the predefined regions revealed a significant interaction.

Effect of Strategy Preference. In addition to the above analysis, differences as a function of strategy preference were also analyzed (see Table 2 and Figure 4). Participants were asked during a debriefing following scanning which strategy, if any, they preferred. Seven participants reported preferring the algebraic strategy, seven the spatial strategy, and three reported having no preference. As a result, the 14 participants with a preference were examined. Within the predefined ROls, the left prefrontal, left anterior insula, and right parietal regions revealed significant effects of preference, with the spatial preference group eliciting greater activation while the left ACC ROI revealed greater involvement for the algebra preference group. Interestingly, these two groups were very similar in terms of their math background (they were asked the highest-level math course they took) and their spatial ability as measured by the Vandenberg mental rotation task $(p>0.6)$. However, there was a difference in working memory capacity as measured by the reading span task ( $p<0.001$ ), with the algebra preference group having a higher span (3.5 and 2.7 for algebra and spatial preference, respectively).

Whole Brain Analysis. In addition to the ROI analysis, whole brain analysis was performed. Using an uncorrected threshold of $p<0.001$ and an extent threshold of greater than 20 voxels, the main effect of strategy revealed three clusters of activation, one in the frontal cortex that extended from the anterior insula anteriorly and superiorly to the middle frontal gyrus, as well as clusters in bilateral superior parietal cortex (see Table 3 and Figure 5). The main effect of difficulty revealed that left prefrontal and left temporal cortices showed greater activation for the hard problems, while regions including the right rostral ACC (which lies more anterior and inferior to the predefined ACC ROI) and bilateral middle/posterior insula revealed greater activation for easy problems. The interaction between the two factors revealed that a number of regions, including bilateral rostral ACC, temporal, and cerebellar regions, showed greater activation for the spatial/hard and algebra/easy problems compared to the spatial/easy and algebra/hard problems.

Ancillary Behavioral Study. A total of 44 individuals participated in the study ( 24 females and 20 males; mean age $=20.8 \pm 4.3$ ). All participants gave informed, written consent approved by the Indiana University IRB.The experimental session consisted of three phases: psychometric testing (the Daneman and Carpenter [1980] reading span [working memory capacity] and the Vandenberg [1971] mental rotations tests); a paper-and-pencil training and debriefing; and the experiment. 
Table 2. Predefined ROls: between-subjects preference analysis

\begin{tabular}{|c|c|c|c|}
\hline \multicolumn{2}{|l|}{ ROI } & \multirow{2}{*}{$\begin{array}{l}\text { Effects: } F(1,6) \\
\text { Preference: } 1.73 \\
\text { Strategy: } 3.94^{*} \\
\text { Difficulty: } 1 \\
\text { Preference*Strategy: }<1 \\
\text { Preference*Difficulty: } 1.53 \\
\text { 3-way: }<1\end{array}$} & \multirow{2}{*}{$\begin{array}{l}\text { MNI coordinates } \\
x, y, z \\
-24,-62,40\end{array}$} \\
\hline Left Superior Parietal Lobe & 7 & & \\
\hline Right Superior Parietal Lobe & 7 & $\begin{array}{l}\text { Preference: } 10.46^{*} \\
\text { Strategy: } 3.05 \\
\text { Difficulty: } 5.33^{*} \\
\text { Preference*Strategy: } 1.23 \\
\text { Preference }{ }^{*} \text { Difficulty: } 4.78^{*} \\
\text { 3-way: }<1\end{array}$ & $26,-54,41$ \\
\hline Left Prefrontal Gyrus & 46 & $\begin{array}{l}\text { Preference: } 60.91^{* *} \\
\text { Strategy: } 18.38^{* *} \\
\text { Difficulty: } 5.32^{*} \\
\text { Preference*Strategy: }<1 \\
\text { Preference*Difficulty: }<1 \\
\text { 3-way: }<1\end{array}$ & $-42,30,24$ \\
\hline Left Anterior Insula & 13 & $\begin{array}{l}\text { Preference: } 17.24^{* *} \\
\text { Strategy: } 15.58^{* *} \\
\text { Difficulty: } 1.51 \\
\text { Preference*Strategy: }<1 \\
\text { Preference*Difficulty: }<1 \\
\text { 3-way: }<1\end{array}$ & $-33,21,6$ \\
\hline Left Anterior Cingulate & 32 & $\begin{array}{l}\text { Preference: } 19.85^{* *} \\
\text { Strategy: } 3.88^{*} \\
\text { Difficulty: }<1 \\
\text { Preference }{ }^{*} \text { Strategy: }<1 \\
\text { Preference }{ }^{*} \text { Difficulty: } 1.05 \\
\text { 3-way: }<1\end{array}$ & $-5,8,47$ \\
\hline Right Anterior Cingulate & 32 & $\begin{array}{l}\text { Preference: }<1 \\
\text { Strategy: } 4.43^{*} \\
\text { Difficulty: }<1 \\
\text { Preference*Strategy: }<1 \\
\text { Preference*Difficulty: }<1 \\
\text { 3-way: }<1\end{array}$ & $5,8,47$ \\
\hline
\end{tabular}

Note: ${ }^{*} p<0.05,{ }^{* *} p<0.0001$.

- volume 3, no. 1 (Fall 2010) 

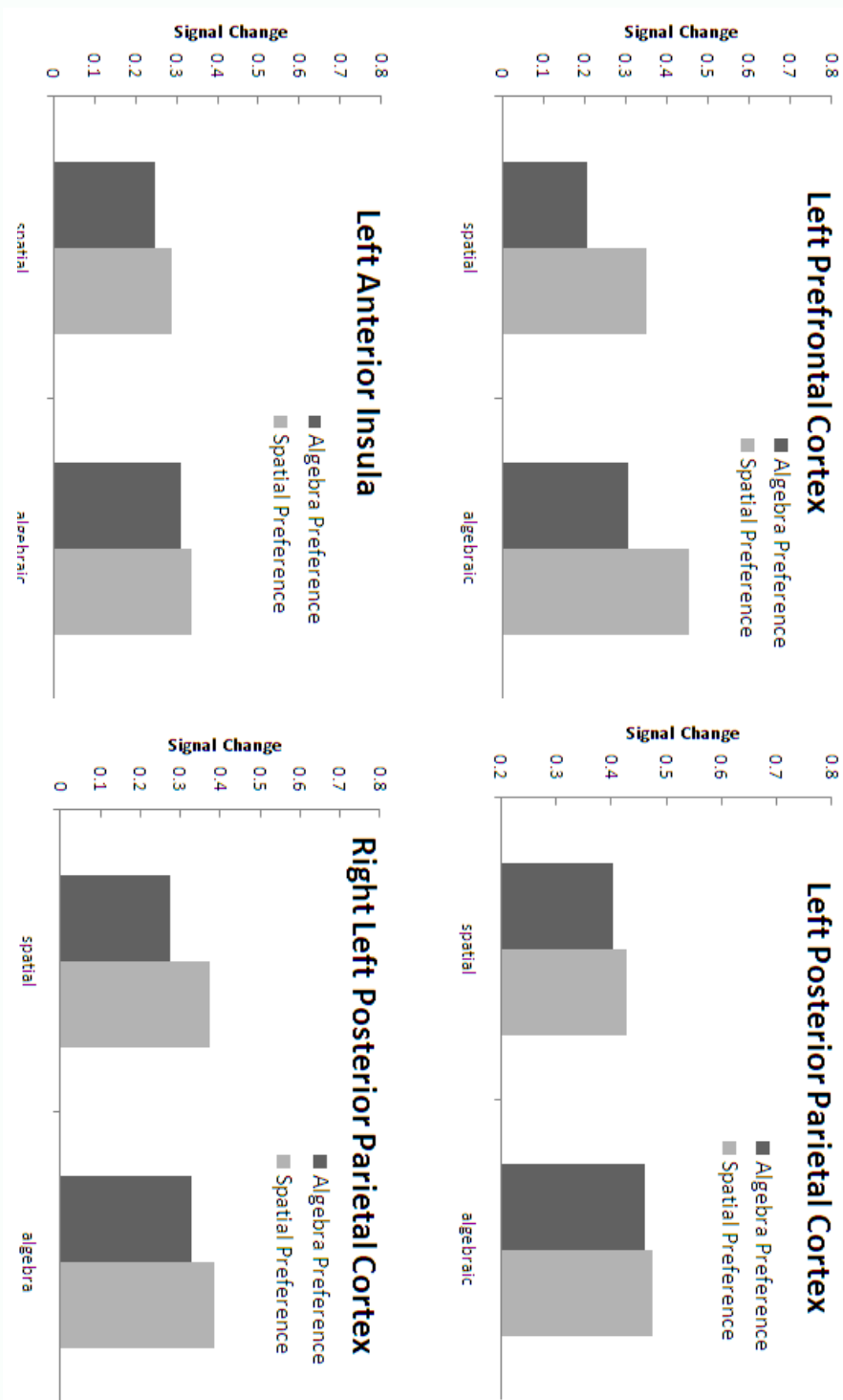

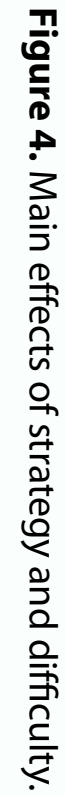

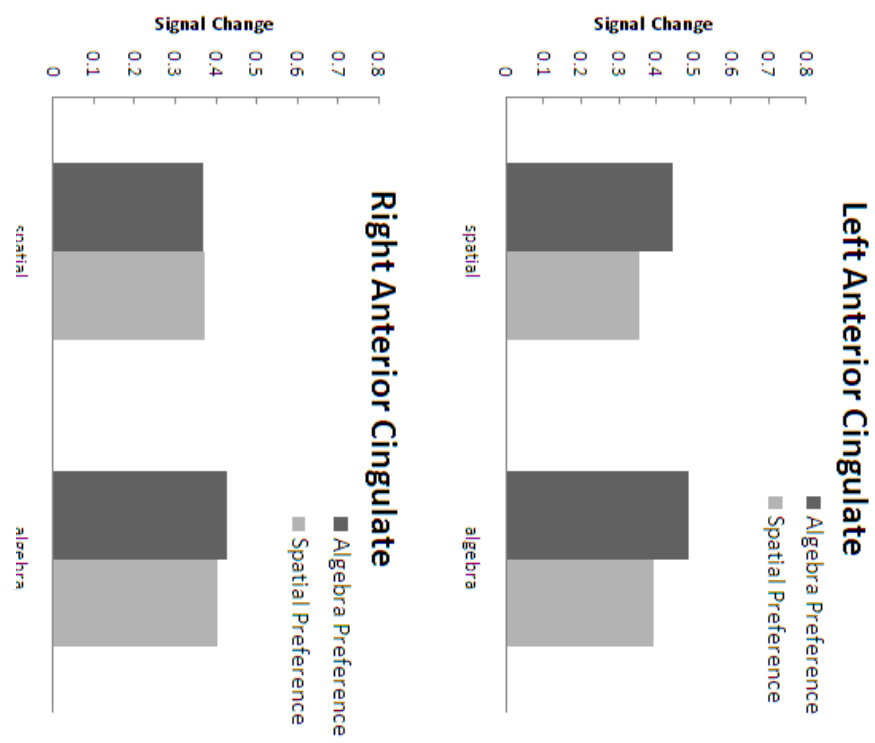

The Journal of Problem Solving • 
Table 3. Exploratory Analysis

\begin{tabular}{|c|c|c|c|c|}
\hline ROI (Brodmann's Area) & & k & $z$ & MNI $x, y, z$ \\
\hline \multicolumn{5}{|c|}{ Strategy effect: Algebra > Spatial } \\
\hline Left Inferior Frontal/Insula & 13 & 315 & 4.18 & $-34,22,6$ \\
\hline Left Middle Frontal Gyrus & 46 & & 4.18 & $-44,32,22$ \\
\hline Left Superior Parietal Cortex & 7 & 549 & 3.95 & $-20,-68,42$ \\
\hline Right Superior Parietal & 7 & 70 & 3.92 & $28,-54,40$ \\
\hline Left Cerebellum & & 27 & 3.66 & $-10,-76,-12$ \\
\hline Left Precentral Cortex & 6 & 45 & 3.46 & $-40,-4,34$ \\
\hline Right Cerebellum & & 41 & 3.41 & $30,-64,-22$ \\
\hline \multicolumn{5}{|c|}{ Difficulty:Hard > Easy } \\
\hline Left Prefrontal Cortex & 46 & 47 & 3.56 & $-46,24,26$ \\
\hline Left Temporal Cortex & 37 & 37 & 3.58 & $-52,-46,-6$ \\
\hline \multicolumn{5}{|l|}{ Difficulty: Easy > Hard } \\
\hline Left Hippocampus & & 208 & 4.79 & $-32,-44,2$ \\
\hline Right Insula & 13 & 326 & 4.44 & $42,10,-6$ \\
\hline Left Insula & 13 & 650 & 4.43 & $-44,0,2$ \\
\hline Left Cerebellum & & 56 & 4.30 & $0,-38,-28$ \\
\hline Left Caudate Nucleus (Tail) & & 171 & 4.25 & $16,-32,20$ \\
\hline Right Caudate Nucleus (Tail) & & 75 & 3.89 & $-12,-30,22$ \\
\hline Right Superior Frontal/ACC & $9 / 32$ & 68 & 3.65 & $20,40,28$ \\
\hline \multicolumn{5}{|c|}{ Interaction between Strategy and Difficulty } \\
\hline Cerebellum & & 140 & 4.3 & $-6,-48,-16$ \\
\hline Left Superior Temporal & 39 & 769 & 4.27 & $-38,-54,30$ \\
\hline Left Middle Temporal Gyrus & 37 & 199 & 4.23 & $-46,-66,8$ \\
\hline Left Hippocampus & & 286 & 4.05 & $-30,-32,-8$ \\
\hline Left Middle Frontal Gyrus & 6 & 135 & 3.98 & $-38,14,44$ \\
\hline Left Medial Frontal/ACC & $9 / 32$ & 101 & 3.97 & $-14,42,22$ \\
\hline Left Anterior Insula & 13 & 70 & 3.87 & $-42,0,-2$ \\
\hline Right Anterior Insula & 13 & 68 & 3.61 & $32,-8,16$ \\
\hline Left Precentral Gyrus & 4 & 92 & 3.55 & $-32,-20,52$ \\
\hline Medial Frontal & 6 & 109 & 3.51 & $0,-28,54$ \\
\hline Left Fusiform Gyrus & 37 & 54 & 3.98 & $-48,-56,-16$ \\
\hline Right Cerebellum & & 36 & 3.73 & $8,-64,-30$ \\
\hline Inferior Frontal Gyrus & 47 & 26 & 3.71 & $-48,42,-8$ \\
\hline Right Medial Frontal/ACC & $10 / 32$ & 53 & 3.7 & $14,46,16$ \\
\hline Left Caudate Nucleus (Body) & & 33 & 3.55 & $-10,8,18$ \\
\hline Left Parietal & 2 & 31 & 3.49 & $-44,-28,54$ \\
\hline Left Insula & 13 & 41 & 3.46 & $-34,-6,18$ \\
\hline Right Middle Temporal & 37 & 23 & 3.42 & $50,-60,6$ \\
\hline
\end{tabular}

- volume 3, no. 1 (Fall 2010) 


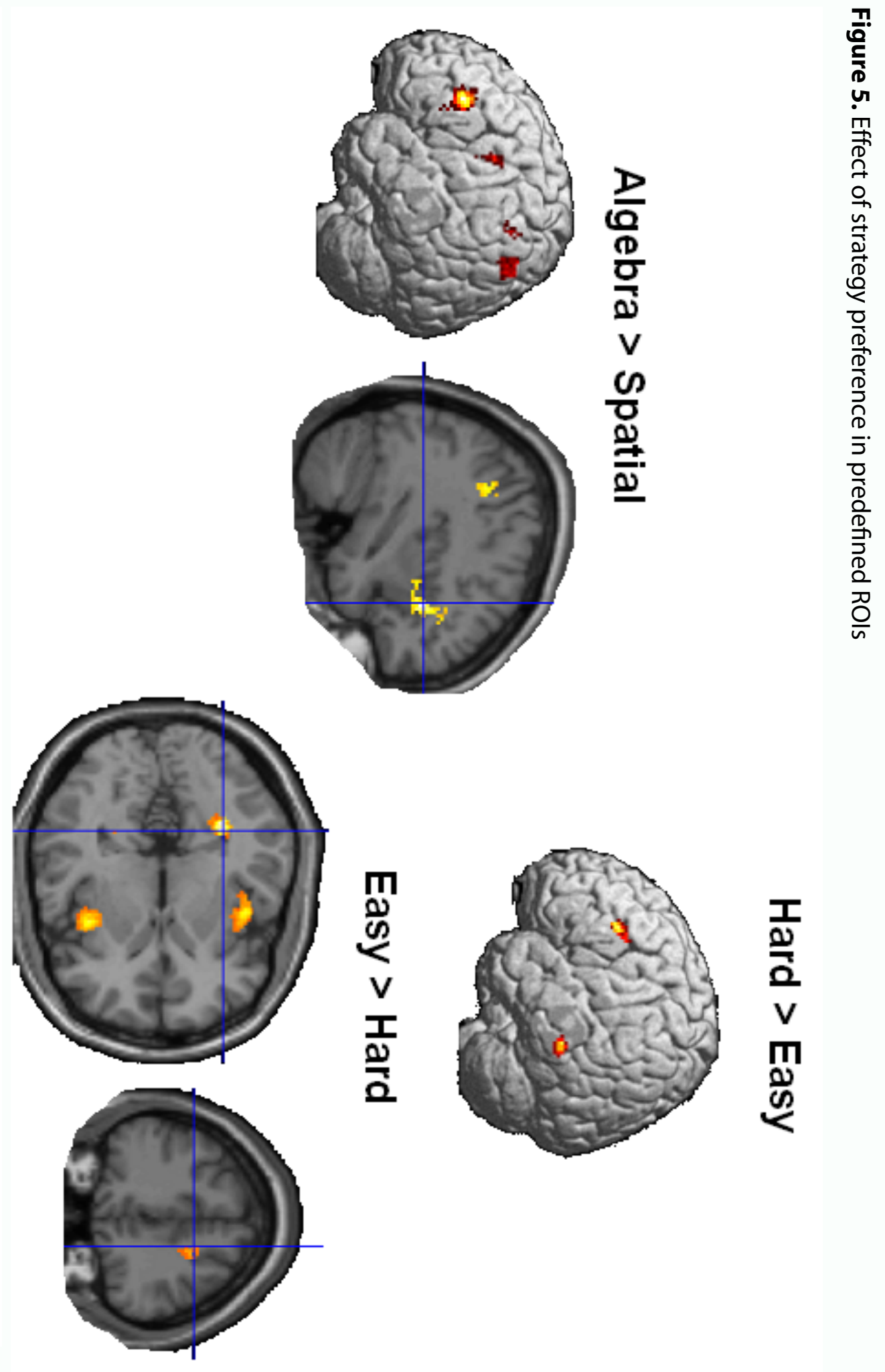

The Journal of Problem Solving • 
The experiment was similar to the imaging study in terms of stimuli used, the order of presentation, and the training procedures, with three exceptions. First, the behavioral study was a self-paced design in which each individual trial was presented in the following manner: phrase 1 (button press), phrase 2 (button press), probe (respond) -in order to obtain processing times for each portion of the problem. Because problem solving is not thought to occur only during the presentation of the probe but actually when reading each phrase and because the timing needs to be controlled during imaging, it is important to obtain these data. The second difference here is that there were no performance cut-offs. After the paper-and-pencil training if participants performed poorly, they were given an opportunity to redo that portion instead of being directed to a different study. Finally, there was no timed computer training session prior to the performance of the experiment.

The reaction time to the probe and the error rate both revealed significant difficulty effects [RT: $F(1,43)=14.11, p<0.001$; error: $F(1,43)=20.85, p<0.0001]$, both failed to show a main effect of strategy $\left[F^{\prime} s<1\right]$, the error data revealed a significant interaction $[F(1,43)$ $=8.55, p<0.01]$. This appears to contradict the results from the scanner; however, when the phrase reading times are examined it is clear that problem solving is taking place during problem presentation (see Figure 6). In fact, phrase 2 revealed a significant effect of strategy $[F(1,43)=13.58, p<0.001]$ and phrase 1 revealed a similar trend such that the algebraic strategy took longer to read. This suggests that the solution may have been generated during phase 2 instead of during the probe phase in this self-paced task due to the lack of time constraints.

Strategy preference was also examined. Here 27 participants reported preferring the algebraic strategy and the remaining 17 reported preferring the spatial strategy; no one reported having no preference. The between-subjects analysis failed to show significant effects of preference; however, each measure revealed an effect of difficulty $(p<0.01)$. This lack of an effect of preference may be due to the unequal group size and the greater variance observed in each group possibly due to the lack of restrictions placed on performance or to participants randomly choosing a preference when they did not have one. In an exploratory analysis, within-participant ANOVAs were performed on each group separately. This analysis revealed that the algebra preference group showed an interaction between strategy and difficulty $[F(1,26)=8.82, p<0.01]$ primarily due to no effect of difficulty when using their preferred strategy. Additionally, the spatial preference group revealed an overadditive interaction for the reading time of phrase $2[F(1,16)=6.84, p<$ 0.01 d due to a greater effect of strategy for the hard compared to the easy problems.

Additionally, the effect of ability indicated some interesting trends. It appears as though working memory capacity had a significant impact on strategy preference. A trend indicating that the high-span participants preferred the algebraic (six out of eight) more so than the spatial strategy was found. This matches the scanner results-the algebra preference group had a higher reading span score than did the spatial preference group.

- volume 3, no. 1 (Fall 2010) 
Figure 6. Ancillary behavioral study error rate and problem reading time (phrase $1+$ phrase 2).

\section{Error Rate}
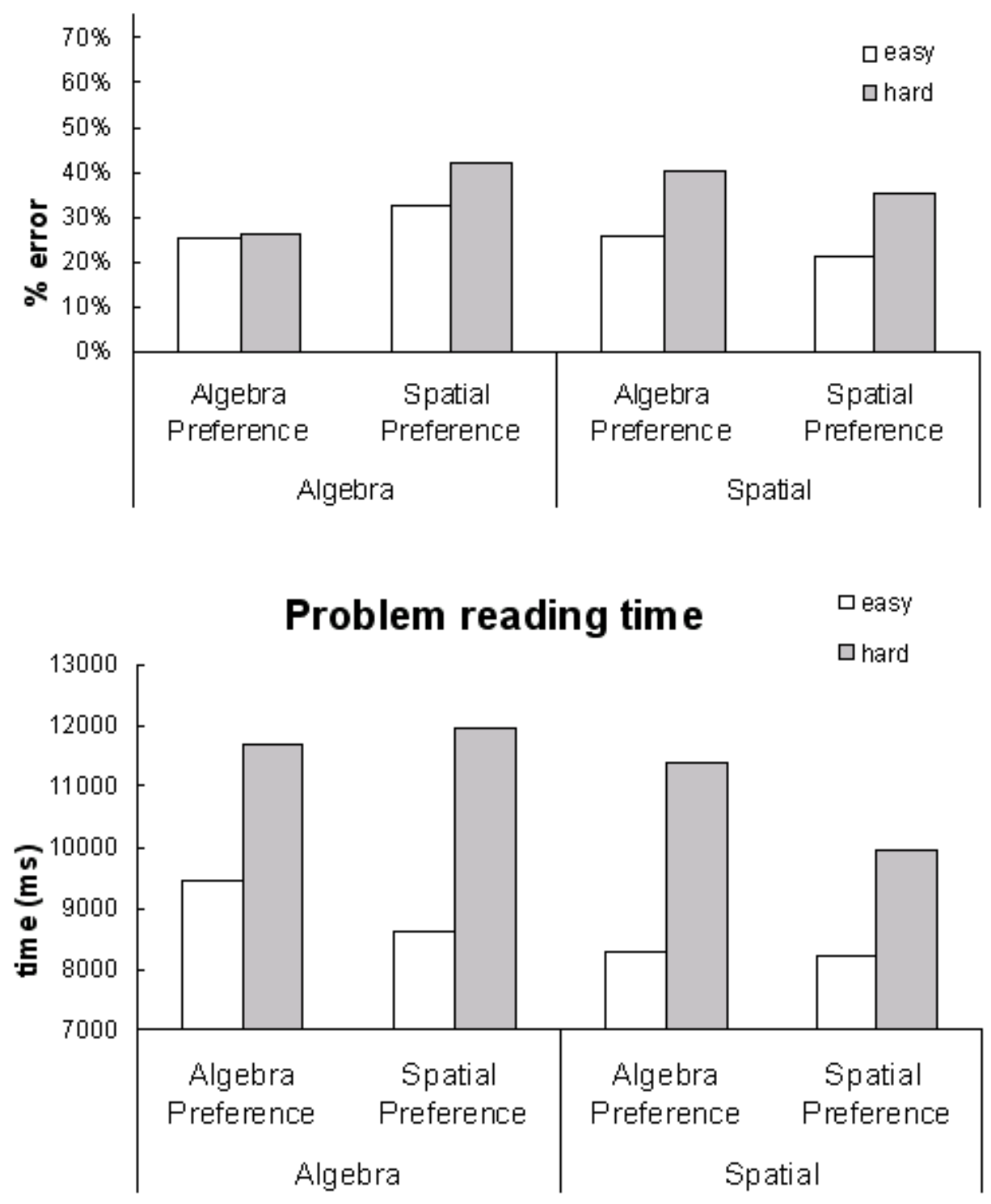

\section{Discussion}

The primary aim of the current study was to examine the influence of strategy differences on the neural network that supports problem solving. Both ROI-based and exploratory analyses revealed similar results-both strategies activated an overlapping cortical network but to differing degrees, with the algebraic strategy eliciting greater activation. As 
expected, both problem-solving strategies recruited similar brain regions. The results demonstrated that, generally, the algebraic strategy was more cognitively demanding than the spatial strategy - if amount of activation is considered to be an indication of demand. Within the predefined regions that correspond to the modules within the ACT-R model we found that the algebra strategy elicited greater involvement of the memory retrieval, mental representation, and setting of controlling goals modules as well as a region linked to verbal working memory. A finding obtained from our exploratory analysis was differences in performance as well as brain activation as a function of strategy preference. It appears that those participants who prefer the algebraic strategy showed less activation and had higher working memory capacity than those who preferred the spatial strategy. Below is a discussion of the strategy differences observed and a discussion of how the current results can be incorporated into the proposed model of problem solving.

The memory retrieval module located in prefrontal cortex is thought to be involved in the controlled retrieval of information from declarative memory (Anderson et al., 2008). The region that is described in the ACT-R model overlaps with regions that have been implicated in studies of semantic retrieval (Wagner et al., 2000; Gold et al., 2006; Badre et al., 2005). For example, in a study conducted by Badre and colleagues it was suggested that the region is involved in "the selection of task-relevant representations from retrieved alternatives" (p. 914). Here the increased load on the memory retrieval module was predicted when using the algebraic strategy. This is because in order to convert the verbal problem to a more mathematical form there is the association of the terms before and after with mathematical terms plus and minus. Making this association is expected to rely on declarative memory systems. In addition, the terms before and after may cause the automatic retrieval of both the addition and subtraction concepts requiring the selection of the appropriate one.

The superior parietal cortices have been linked to the representational processes within the ACT-R model. In a previous model of ours of the Tower of London (Newman et al.,2003) we hypothesized that the right parietal cortex is more involved in the control of spatial attention and the geometric manipulation of spatial representations (Carpenter et al., 1999; Zachs, 2008), whereas the left parietal cortex is more involved with constructing and maintaining spatial representations (Anderson et al., 2008). The neuroimaging data from that study supported this hypothesis. In the current study further support for this hypothesis was found. The effect of strategy revealed that the algebraic strategy elicited greater activation of the representational module. When examining the steps involved in both strategies (see Figure 1) it becomes apparent that for the spatial strategy the representation generated, the number line, requires fewer, less complex manipulations (moving the ball from one bin to another). The algebraic strategy, on the other hand, requires the generation and transformation of an algebraic equation. These transformations significantly change the internal representation of the problem. Other support for

- volume 3, no. 1 (Fall 2010) 
the idea that the algebraic strategy places greater demands on representation processing comes from the ancillary behavioral study. In the behavioral study the reading times for each phrase were longer for the algebraic strategy than the spatial strategy, suggesting that problem transformation takes longer when using the algebraic strategy. In addition, the parietal cortex has been found in previous studies to be significantly involved specifically in algebra problem solving and has been linked to problem transformation (Danker \& Anderson, 2007).

The anterior cingulate cortex is another region that revealed significant strategy effects, with the algebraic strategy showing greater activation. This region, based on the ACT-R model, is responsible for setting of controlling goals; in previous studies it has been linked to cognitive control processes generally (MacDonald et al.,2000) and error detection (Gehring et al., 1993) or error likelihood (Brown \& Braver, 2005) more specifically. Anderson points out that a consistent finding of his is that the activation of the ACC is not affected by practice (Anderson et al.,2008) and that this resistance to practice effects supports the region's association with control processes because "control states depend upon how the various steps are articulated in a strategy, and they stay constant unless the strategy itself is modified" (p. 140). This is an interesting observation because here we find effects of strategy in this region but not difficulty. The question now is why is there greater demand on control processes when using the algebraic strategy compared to the spatial strategy? When the steps to solve the problems for each strategy are examined (see Figure 1), it becomes clear that because of the conversion of the problem into an equation, there are more steps. If the ACC is involved in controlling the order of these steps and ensures that they are all performed appropriately, then this may explain the greater involvement for the algebraic strategy. However, it could also very well be that because there are more steps there is a higher likelihood of error. The behavioral data provide some support for this hypothesis. When examining the scanner behavioral data it appears as though there may be a speed-accuracy tradeoff due to the spatial strategy having a longer response time to the probe but also fewer errors than the algebraic strategy. This increase in errors for the algebraic strategy may be directly related to the increased number of steps, which increases the likelihood for committing an error.

While the ACC revealed significant effects of strategy, the region failed to show difficulty effects, which were predicted. If it is involved in error processing, then it is difficult to explain why there was no difficulty effect given that the probability of error is greater for the hard compared to the easy problems, at least the error rate is significantly higher. The ACC is a heterogeneous structure that can be divided into dorsal (dACC) and rostral (rACC) regions based on both function and connectivity (Bush, Luu, \& Posner, 2000). The $\mathrm{dACC}$, which is the region described in the ACT-R model, is the more posterior part of the region and connects with the lateral prefrontal cortex and hippocampus to regulate effortful cognitive operations. The rACC lies anterior to the dACC and is connected with the 
amygdala, middle/posterior insula, and ventral striatum and has been suggested to reflect appraisal of the affective or motivational significance of errors (van Veen and Carter, 2002; Luu et al.,2003; Taylor et al.,2006). While the dACC revealed significant strategy effects, the rACC revealed a significant effect of difficulty (easy greater than hard) and an interaction such that there was greater activation for the algebra easy and the spatial hard compared to the algebra hard and spatial easy (see Table 3). These results show the complex nature of the contribution of the ACC in problem solving and suggest an influence of not just cognitive control but also a possible role of emotional regulation.

The anterior insula has been found to be active in a number of sentence-level processing tasks, particularly in studies examining syntactic complexity (Newman, Lee, \& Ratcliffe, 2009; Lee \& Newman, 2010). There the region has been implicated in sentence working memory processes that are required during comprehension. Therefore, it seems that these sentence-level comprehension processes are collaborating with the imaginal processes to generate the equation and that this transformation of the sentence into an equation is more demanding than the transformation to a more pictorial representation (as is required for the spatial strategy). As mentioned earlier, the anterior insula is thought to be involved in working memory processes related to manipulation or transformations of the generated internal representations. Another possible explanation for the anterior insula's increased involvement for the algebraic strategy may be related to the region's link to verbal working memory. It may be that algebra problem solving relies heavily on verbal working memory while the spatial strategy does not. In fact, working memory resources have been thought to play a role in retrieving arithmetic facts from long-term memory (Barrouillet, Benardin, \& Camos, 2004; Kaufmann, et al., 2003; Imbo \& Vandierendonck, 2007).

Strategy Preference. The examination of strategy preference was exploratory in nature. However, it did reveal some very interesting trends that deserve discussion and further investigation. First, because of the apparent relationship between strategy preference and working memory capacity it is not at all clear to which of the two to attribute the differences observed. However, we favor the interpretation that ability, in this case working memory capacity, influences strategy preference and, therefore, the effects of preference are actually working memory capacity effects.

Individual differences in ability have been found to play a role in strategy selection as well as strategy formation. While only a few studies have examined the effect of working memory on arithmetic strategy selection, it has been found that working memory does have an impact (Imbo \& Vandierendonck, 2008a, 2008b; Hecht, 2002; Seyler, Kirk, \& Ashcraft, 2003). For example, during arithmetic problem solving, higher working memory capacity participants used a retrieval strategy more often than low-span participants (Imbo \& Vandierendonck, 2008b). One possible explanation as to the role working memory plays in strategy selection is its relationship to attentional resources (Anderson, 1993). If high-

- volume 3, no. 1 (Fall 2010) 
span individuals have greater attentional resources, then they have a greater resource pool to draw from during strategy execution, which may allow them to be more efficient problem solvers. They may also be better able to inhibit or suppress irrelevant information (Engle, 2001; Engle, Kane, \& Tuholski, 1999). Some support for this idea has come from studies showing that children with mathematical disability have poor performance on working memory tasks (Geary \& Brown, 1991; Geary, Hoard, \& Hamson, 1999; Hitch \& McAuley, 1991; Siegel \& Ryan, 1989). In the current study differences as a function of strategy preference were found in the left prefrontal region (memory retrieval module) and the anterior insula (a working memory region). This result supports the hypothesis that working memory capacity may play a role in strategy use but it may also play a role in strategy preference.

Conclusions. The current study demonstrates that although these two distinct problem-solving strategies elicited activation of overlapping neural structures, the level of involvement of these structures was a function of strategy. As it relates to the ACT-R model of problem solving the results presented here support the previous findings. They also suggest some extensions in that the anterior insula appears to play a large role in problem solving as it relates to working memory.

The effects of strategy preference are difficult to interpret, primarily due to the small number of participants examined and the exploratory nature of the analysis. However, the results are intriguing because they suggest that strategy preference can have a significant impact on problem-solving performance and that using a non-preferred strategy is more effortful and may lead to increased errors. This result could have significant implications in pedagogy, particularly in the instruction of mathematics. In addition, the trends observed in both the scanner and behavioral studies showing that preference is related to working memory capacity suggest links between ability and strategy preference. This opens the possibility of being able to predict preference.

There are some limitations of the study. As with any study that examines strategy it is difficult to ensure that participants are using the strategy they are instructed to use. That was also a concern here. Although we trained participants in the imaging study well and debriefed participants extensively, we still cannot be sure that they all followed instructions. In addition, as stated above, the preference analysis was exploratory and there were only a few subjects in each preference group. As a result conclusions should be made with caution. In fact, they are presented here to encourage further study of the effect of strategy preference, and not to make conclusions regarding the meaning of the results.

Greater insight into the underlying differences between the two strategies as well as the effect of strategy preference may be obtained by examining differences in the types of errors committed when using each strategy and by the different preference groups. This type of analysis was not possible with the current design or with fMRI, generally, due to the inability to have participants write out their problem-solving steps as well as due 
to the time constraints during imaging. However, important insights may be gained in determining the proportion of errors due to computational slips, reading comprehension errors, and conceptual reasoning errors.

\section{References}

Anderson, J. R. (1993). Rules of the mind. Hillsdale, NJ: Erlbaum.

Anderson, J.R., Fincham, J. M., Qin, Y., \& Stocco, A. (2008). A central circuit of the mind. Trends in Cognitive Science, 12, 136-143.

Anderson, J. R., Qin, Y., Stenger, A., \& Carter, C. S. (2004). The relationship of three cortical regions to an information-processing model. Journal of Cognitive Neuroscience, 16, 637-653.

Awh, E., Smith, E.E., Koeppe, R. A., Schumacher, E.H., \& Katz, S. (1996):Dissociation of storage and rehearsal in verbal working memory: Evidence from PET. Psychological Science, 7, 125-131.

Badre, D., Poldrach, R. A., Pare-Blagoev, E. J., Insler, R. Z., \& Wagner, A. D. (2005) Dissociable controlled retrieval and generalized selection mechanisms in ventrolateral prefrontal cortex. Neuron, 47, 907-918.

Barrouillet, P., Benardin, S., \& Camos,V.(2004).Time constraints and resource sharing in adults' working memory span. Journal of Experimental Psychology: General, 133, 83-100.

Botvinick, M. M., Braver, T.S., Barch, D. M., Carter, C.S., \& Cohen, J.D. (2001). Conflict monitoring and cognitive control. Psychological Review, 108, 624-652.

Brett, M., Anton, J.L.,Valabregue, R., \& Poline, J.B. (2002). Region of interest analysis using an SPM toolbox (Abstract). Presented at the 8th International Conference on Functional Mapping of the Human Brain, Sendai, Japan.

Brown, J. W., \& Braver, T. S. (2005). Learned predictions of error likelihood in the anterior cingulate cortex. Science, 307, 1118-1121.

Bush, G., Luu, P., \& Posner, M. I. (2000). Cognitive and emotional influences in anterior cingulate cortex. Trends in Cognitive Science, 4, 215-222.

Carpenter, P.A., Just, M. A., \& Reichle, E. D. (2000). Working memory and executive function: Evidence from neuroimaging. Current Opinion in Neurobiology, 10, 195-199.

Carpenter, P. A., Just, M. A., Keller,T. A., Eddy,W.F., \& Thulborn, K. R. (1999). Graded functional activation in visuo-spatial system with the amount of task demand. Journal of Cognitive Neuroscience, 11, 9-24.

Carpenter,P.A., \& Just, M. A. (1977).Integrative processes in comprehension. In D. LaBerge \& S.J.Samuels (Eds.), Basic processes in reading:Perception and comprehension. Hillsdale, NJ:Erlbaum.

Casey, P.J. (1993)."That man's father is my father's son": The role of structure, strategy, and working memory in solving convoluted verbal problems. Memory and Cognition, 21, 506.

- volume 3, no. 1 (Fall 2010) 
Clark, H., \& Haviland, S. (1977). Comprehension and the given-new contract. In R. Freedle (Ed.), Discourse production and comprehension. Norwood, NJ: Ablex.

Daneman, M., \& Carpenter, P.A. (1980). Individual differences in working memory and reading. Journal of Verbal Learning and Verbal Behavior, 19, 450-466.

Danker, J. F., \& Anderson, J.R. (2007). The roles of prefrontal and posterior parietal cortex in algebra problem solving: A case of using cognitive modeling to inform neuroimaging data. Neurolmage, 35, 1365-1377.

D’Esposito, M., Postle, B. R., Jonides, J., \& Smith, E.E.(1999). The neural substrate and temporal dynamics of interference effects in working memory as revealed by event-related functional MRI. Proceedings of the National Academy of Sciences USA, 96, 7514-7519.

Engle, R.W.(2001).What is working memory capacity? In H.L. Roediger III, J.S. Nairne, I. Neath, \& M.Surprenant (Eds.), The nature of remembering: Essays in honor of Robert G. Crowder (pp. 297-314).Washington, DC: American Psychology Association.

Engle, R. W., Kane, M. J., \& Tuholski, S. W. (1999). Individual differences in working memory capacity, what they tell us about controlled attention, general fluid intelligence, and functions of the prefrontal cortex. In A. Miyake \& P. Shah (Eds.), Models of working memory:Mechanisms of active maintenance and executive control (pp.102-134).Cambridge: Cambridge University Press.

Friston, K. J., Holmes, A. P., Worsley, K. J., Poline, J. P., Frith, C. D., \& Frackowiak, R. S. J. (1995). Statistical parametric maps in functional imaging: A general linear approach. Human Brain Mapping, 2, 189-210.

Geary, D. C., \& Brown, S. C. (1991). Cognitive addition-Strategy choice and speed-ofprocessing differences in gifted, normal, and mathematically disabled-children. Developmental Psychology, 27, 398-406.

Geary, D.C., Hoard, M. K., \& Hamson, C.O. (1999). Numerical and arithmetical cognition:Patterns of functions and deficits in children at risk for a mathematical disability.Journal of Experimental Child Psychology, 74, 213-239.

Gehring, W. J., Goss, B., Coles, M. G. H., Meyer, D. E., \& Donchin, E. (1993). A neural system for error detection and compensation. Psychological Science, 4, 385-390.

Gold, B. T., \& Buckner, R. L. (2002). Common prefrontal regions coactivate with dissociable posterior regions during controlled semantic and phonological tasks. Neuron, 35, 803-812.

Gold, B. T., Balota, D. A., Jones, S. J., Powell, D. K., Smith, C. D., \& Andersen, A. H. (2006). Dissociation of automatic and strategic lexical semantics: $f M R I$ evidence for differing roles of multiple frontotemporal regions. Journal of Neuroscience, 26, 6523-6532.

Graham, T., \& Perry, M. (1993). Indexing transitional knowledge.Developmental Psychology, 29, 779-788.

Haviland, S.E. and Clark, H.H. (1974). What's new? Acquiring new information as a process in comprehension. Journal of Verbal Learning and Verbal Behavior, 13, 512-521. 
Hecht, S. A. (2002). Counting on working memory in simple arithmetic when counting is used for problem solving. Memory and Cognition, 30, 447-455.

Hitch, G. J., \& McAuley, E. (1991). Working memory in children with specific arithmetical difficulties. British Journal of Psychology, 82, 375-386.

Imbo, I., \& Vandierendonck, A. (2007). The role of phonological and executive working memory resources in simple arithmetic strategies. European Journal of Cognitive Psychology, 19, 910-933.

Imbo, I., \& Vandierendonck, A. (2008a). Practice effects on strategy selection and strategy efficiency in simple mental arithmetic. Psychological Research, 72, 528-541.

Imbo, I., \& Vandierendonck, A. (2008b). Effects of problem size, operation, and workingmemory span on simple-arithmetic strategies: Differences between children and adults? Psychological Research, 72, 331-346.

Kaufmann, L., Lochy, A., Drexler, A., \& Semenza, C. (2003). Deficient arithmetic fact retrieval-Storage or access problem? A case study. Neuropsychologia, 42, 482-496.

Koedinger, K. R., \& Terao, A. (2002). A cognitive task analysis of using pictures to support pre-algebra reasoning. In Proceedings of the Twenty-Fourth Annual Conference of the Cognitive Science Society (pp. 542- 547). Mahwah, NJ: Lawrence Erlbaum Associates.

Kwong, T. E., \& Varnhagen, C. K. (2005). Strategy development and learning to spell new words: Generalization of a process. Developmental Psychology, 41, 148-159.

Lee, D., \& Newman, S.D. (2010). The effect of presentation paradigm on syntactic processing: An event-related fMRI study. Human Brain Mapping,31, 123-132.

LeFevre, J.-A., Bisanz, J., Daley, K. E., Buffone, L., Greenham, S. L., \& Sadesky, G. S. (1996). Multiple routes to solution of single digit multiplication problems. Journal of Experimental Psychology: General, 125, 284-306.

Lewis, A. B. (1989). Training students to represent arithmetic word problems. Journal of Educational Psychology, 81, 521-531.

Luu, P., Tucker, D. M., Derryberry, D., Reed, M., \& Poulsen, C. (2003). Electrophysiological responses to errors and feedback in the process of action regulation. Psychological Science, 14, 47-53.

MacDonald, A. W., Cohen, J. D., Stenger, V. A., \& Carter, C. S. (2000). Dissociating the role of the dorsolateral prefrontal and anterior cingulate cortex in cognitive control.Science, 288, 1835-1838.

Newman, S.D., Lee, D., Bates, L.C. (2007). The timecourse of activation within the cortical network associated with visual imagery. The Online Neuroimaging Journal, 1, 1-9.

Newman, S.D., Carpenter, P.A ., Varma, S., \& Just, M. A. (2003). Frontal and parietal participation in problem-solving in the Tower of London: $\mathrm{fMRI}$ and computational modeling of planning and high-level perception. Neuropsychologia, 41(12), 1668-1682.

Newman, S. D., Greco, J. A., \& Lee, D. (2009). An fMRI study of the Tower of London: A look at problem structure differences. Brain Research, 1286, 123-132.

- volume 3, no. 1 (Fall 2010) 
Newman, S.D., Just, M. A., \& Carpenter, P. A. (2002). The synchronization of the human cortical working memory network. Neurolmage, 15, 810-822.

Newman,S.D.,Lee,D., \& Ratliff,K.(2009). How much does the comprehension probe interact with on-line syntactic processing? Human Brain Mapping, 30, 2499-2511.

Postle, B. R., Berger, J. S., \& D’Esposito M. (1999). Functional neuroanatomical double dissociation of mnemonic and executive control processes contributing to working memory performance. Proceedings of the National Academy of Sciences USA, 96, 12959-12964.

Qin, Y., Carter, C. S., Silk, E. M., Stenger, V. A., Fissell, K., Goode, A., \& Anderson, J. R. (2004). The change of the brain activation patterns as children learn algebra equation solving, Proceedings of the National Academy of Sciences USA, 101, 5686-5691.

Rogers, W. A., Hertzog, C., \& Fisk, A. D. (2000). An individual differences analysis of ability and strategy influences: Age-related differences in associative learning. Journal of Experimental Psychology: Learning, Memory, \& Cognition, 26, 359-394.

Rosenberg-Lee, M., Lovett, M. C., \& Anderson, J. R. (2009). Neural correlates of arithmetic calculation strategies. Cognitive, Affective, \& Behavioral Neuroscience, 9, 270-285.

Seyler,D.J., Kirk, E.P., \& Ashcraft, M.H. (2003). Elementary subtraction. Journal of Experimental Psychology: Learning, Memory, and Cognition, 29, 1339-1352.

Siegel, L. S., \& Ryan, E. B. (1989). The development of working memory in normally achieving and subtypes of learning disabled children. Child Development, 60, 973-980.

Siegler, R.S. (1995). How does change occur:A microgenetic study of number conservation. Cognitive Psychology, 28, 255-273.

Siegler, R. S., Adolph, K. E., \& Lemaire, P. (1996). Strategy choices across the life span. In L.E. Reder (Ed.), Implicit memory and metacognition. Hillsdale, NJ: Erlbaum.

Smith, E. E., \& Jonides, J. (1999). Storage and executive processes in the frontal lobes. Science, $283,1657-1661$.

Stocco, A., \& Anderson, J. R. (2008). Endogenous control and task representation: An fMRI study in algebraic problem-solving. Journal of Cognitive Neuroscience, 20, 13001314.

Taylor, S. F., Martis, B., Fitzgerald, K. D,. Welsh, R. C., Abelson, J. L., Liberzon, I., et al. (2006). Medial frontal cortex activity and loss-related responses to errors.Journal of Neuroscience, 26, 4063-4070.

van Veen,V., \& Carter,C.S.(2002).The timing of action-monitoring processes in the anterior cingulate cortex. Journal of Cognitive Neuroscience, 14, 593-602.

Vandenberg, S. G. (1971). Mental rotation test. Boulder: University of Colorado.

Wagner, A. D., Koutstaal, W., Maril. A., Schacter, D. L., \& Buckner, R. L. (2000). Task-specific repetition priming in left inferior prefrontal cortex. Cerebral Cortex, 10, 1176-1184.

Zachs, J. M. (2008). Neuroimaging studies of mental rotation: A meta-analysis and review. Journal of Cognitive Neuroscience, 20, 1-19. 